\title{
Interplay between nanoscale reactivity and bulk performance of H-ZSM-5 catalysts during the methanol-to-hydrocarbons reaction
}

\author{
Luis R. Aramburo ${ }^{\text {, }}$, Shewangizaw Teketel ${ }^{\mathrm{b}}$, Stian Svelle ${ }^{\mathrm{b}}$, Simon R. Bare ${ }^{\mathrm{c}}$, Bjørnar Arstad ${ }^{\mathrm{d}}$, \\ Henny W. Zandbergen ${ }^{\mathrm{e}}$, Unni Olsbye ${ }^{\mathrm{b}}$, Frank M.F. de Groot ${ }^{\mathrm{a}}$, Bert M. Weckhuysen ${ }^{\mathrm{a}, *}$

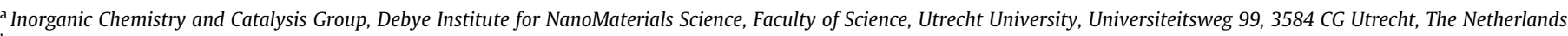 \\ ${ }^{\mathrm{b}}$ inGAP Center for Research Based Innovation, Department of Chemistry, University of Oslo, N-0315 Oslo, Norway \\ 'UOP LLC, a Honeywell Company, Des Plaines, IL 60017, USA \\ ${ }^{\mathrm{d}}$ Department of Process Chemistry SINTEF Materials \& Chemistry, 0314 Oslo, Norway \\ ${ }^{\mathrm{e}}$ Kavli Institute of NanoScience, National Centre for High Resolution Electron Microscopy, Delft University of Technology, PO Box 5046,2600 GA Delft, The Netherlands
}

\section{A R T I C L E I N F O}

\section{Article history:}

Received 31 October 2012

Revised 7 July 2013

Accepted 12 July 2013

Available online 26 August 2013

\section{Keywords:}

Heterogeneous Catalysis

Zeolites

Methanol-to-hydrocarbons

Coke formation

In situ spectroscopy

\begin{abstract}
A B S T R A C T
H-ZSM- 5 catalyst powders before and after a steaming post-treatment have been investigated during the Methanol-To-Hydrocarbons (MTH) process at $350^{\circ} \mathrm{C}$. Bulk and surface characterization techniques have been combined with in situ Scanning Transmission X-ray Microscopy (STXM) at the aluminum and carbon K-edge to study the changes in acidity, porosity, reactivity, and aluminum distribution upon steaming. It was found that steaming post-treatment has a positive impact on the stability of H-ZSM-5 without inducing important changes in the MTH activity and selectivity. The lower MTH stability of non-steamed H-ZSM-5 catalyst powder is related to the formation of poly-aromatic compounds in the outer regions of the catalyst particles, as probed with in situ STXM. In contrast, a limited amount of poly-aromatics was found in the outer rim of steamed H-ZSM- 5 catalyst particles. These differences occur as a result of the generation of mesoporosity as well as the reduction in the number and strength of acid sites after steaming, as evidenced by the nanoscale imaging of adsorbed pyridine with STXM.
\end{abstract}

(c) 2013 Elsevier Inc. All rights reserved.

\section{Introduction}

The Methanol-To-Hydrocarbons (MTH) process has attracted both industrial and academic interest as methanol can be produced at a large scale from syngas by the direct oxidative conversion of methane or by the reductive conversion of atmospheric carbon dioxide with hydrogen [1]. Depending on the reaction conditions and the type of catalyst used in the MTH process, methanol can be transformed into olefins (MTO), gasoline (MTG), or other value-added chemicals [2,3]. Since the first oil crisis, zeolite materials have been extensively studied as promising catalysts for the MTH process $[4,5]$. Among them, H-ZSM-5 is considered as one of the archetypal catalyst to conduct the MTH reaction [4]. Nonetheless, the generation of undesired carbon deposits often leads to severe diffusion restrictions and fast deactivation rates. As a result, H-ZSM-5 needs to be regenerated, which frequently induces leaching of framework $\mathrm{Al}$ species, resulting in important variations in activity, selectivity as well as overall stability [6,7].

In the present work, the effect that a mild hydrothermal treatment has on the MTH stability of relevant zeolite H-ZSM-5 catalyst

\footnotetext{
* Corresponding author. Fax: +3130251 1027.

E-mail address: b.m.weckhuysen@uu.nl (B.M. Weckhuysen).
}

powders has been investigated in detail. We compare the reactivity of a calcined (sample name: $\mathrm{H}-\mathrm{ZSM}-5-\mathrm{C}$ ) and a mildly steamed (sample name: H-ZSM-5-500) catalyst powder during the MTH reaction at $350{ }^{\circ} \mathrm{C}$ by catalytic testing and in situ Scanning Transmission X-ray Microscopy (STXM) at the carbon and aluminum $\mathrm{K}$-edges as well as by a range of bulk and surface characterization methods. This unique experimental approach allows proposing an explanation of the large differences noticed in MTH stability between H-ZSM-5-C and H-ZSM-5-500 in terms of nanoscale differences in the type and amount of hydrocarbon deposits in addition to the number and strength of acid sites within individual zeolite H-ZSM-5 aggregates.

\section{Experimental}

\subsection{Materials}

Two different zeolite H-ZSM-5 aggregate materials, namely a calcined material (i.e., H-ZSM-5-C) and a mildly steamed material (i.e., H-ZSM-5-500), have been investigated. The starting material, with crystallite dimensions of approximately $200-800 \mathrm{~nm}$, is a commercial zeolite $\mathrm{NH}_{4}$-ZSM- 5 catalyst powder provided by Zeolyst $(\mathrm{CBV} 2314, \mathrm{Si} / \mathrm{Al}=11.5)$. To obtain $\mathrm{H}-\mathrm{ZSM}-5-\mathrm{C}$, the starting 
material was calcined in a static oven (N100 Nabertherm) first preheating it at $120^{\circ} \mathrm{C}\left(30 \mathrm{~min}, 2^{\circ} \mathrm{C} / \mathrm{min}\right)$ and then increasing the temperature to $550{ }^{\circ} \mathrm{C}\left(360 \mathrm{~min}, 10^{\circ} \mathrm{C} / \mathrm{min}\right)$. The steamed sample was prepared treating H-ZSM-5-C in a quartz tubular oven (Thermoline 79300) during $180 \mathrm{~min}$ at $500{ }^{\circ} \mathrm{C}$ via saturation of a nitrogen flow $(180 \mathrm{ml} / \mathrm{min})$ with water at $100^{\circ} \mathrm{C}$. Prior to steaming, the sample was preheated at $120^{\circ} \mathrm{C}\left(30 \mathrm{~min}, 2^{\circ} \mathrm{C} / \mathrm{min}\right)$. After the hydrothermal treatment, the sample was calcined following the same procedure as that described to obtain H-ZSM-5-C.

\subsection{X-ray diffraction}

X-ray diffraction (XRD) patterns were obtained at room temperature from $5^{\circ}$ to $90^{\circ} 2 \theta$ with a Bruker-AXS D8 Advance powder $\mathrm{X}$-ray diffractometer, equipped with an automatic divergence slit, a Våntec- 1 detector and a Cobalt $\mathrm{K} \alpha 1,2(\lambda-1.79026 \AA)$ source.

\subsection{Nitrogen physisorption}

Nitrogen adsorption and desorption isotherms were measured at $-196^{\circ} \mathrm{C}$ on a Micromeritics Tristar 3000 instrument.

\subsection{Catalytic testing}

Catalytic testing experiments were performed on the powders without pressing and sieving the two catalyst materials under study. For each experiment, $30 \mathrm{mg}$ of catalyst was placed in a fixed-bed reactor, activated at $550{ }^{\circ} \mathrm{C}$ under oxygen for $1 \mathrm{~h}$, and then cooled to the reaction temperature $\left(350^{\circ} \mathrm{C}\right)$. The MTH reaction products were analyzed with an online gas chromatograph (GC) connected to the outlet of a fixed-bed reactor (i.d. $6 \mathrm{~mm}$ ) using a heated transfer line. The inlet of the reactor was connected to helium, which was bubbled through methanol kept at $20^{\circ} \mathrm{C}\left(P_{\mathrm{MeOH}}=130 \mathrm{mbar}\right)$ in a saturation evaporator (WHSV $=5.56 \mathrm{~g} \mathrm{~g}^{-1} \mathrm{~h}^{-1}$ ).

To analyze the coke after reaction, $15 \mathrm{mg}$ of the deactivated catalyst samples was transferred into a Teflon tube where $1 \mathrm{ml}$ of $15 \%$ hydrofluoric acid was added. Subsequent to a waiting time of $30 \mathrm{~min}, 1 \mathrm{ml}$ of dichloromethane, containing hexachloroethane as the internal standard, was added to the Teflon tube. Then, $1 \mu \mathrm{l}$ of the resulting organic phase was analyzed in an Agilent 6890N GC equipped with an Agilent 5793 Mass Selective Detector. A HP5MS column $(60 \mathrm{~m}, 0.25 \mathrm{~mm}$ i.d., stationary phase thickness $0.25 \mu \mathrm{m}$ ) and an inlet split of 1:5 were used for this purpose.

\subsection{Scanning transmission X-ray microscopy}

In a first set of in situ STXM experiments, the MTH reaction was performed on the interferometrically controlled STXM microscope at the Pollux beamline of the Swiss Light Source (SLS, Villigen, Switzerland) [8]. For this purpose, a Micro-Electro-Mechanical System (MEMS) nanoreactor was used to characterize the catalytic behavior of the two zeolite H-ZSM-5 catalyst powders under study. Prior to reaction, the samples were introduced inside the nanoreactor and placed in an adaptor that can be translated with nanometer precision by an interferometrically controlled $(x, y, z)$ piezoelectric stage. The samples were activated at $450{ }^{\circ} \mathrm{C}$ flowing helium $(2 \mathrm{ml} /$ min) during $30 \mathrm{~min}$. Then, the temperature was decreased to $350{ }^{\circ} \mathrm{C}$, and methanol (Antonides-Interchema, 99\%) was introduced via saturation of helium flow $\left(2 \mathrm{ml} / \mathrm{min}\right.$ ) at $0^{\circ} \mathrm{C}$ for $400 \mathrm{~min}$. During reaction, the absorption at the carbon K-edge was analyzed at different times on stream collecting a series of images over small energy increments, subsequently combining these images to form a spectral image sequence (stack). The stacks were obtained in the range of 280-310 eV using an energy resolution of $0.2 \mathrm{eV}$. In a second step, a Principal Component Analysis (PCA) and a cluster analysis were performed to classify pixels according to statistical similarities in their spectra. During the measurements, the monochromized X-ray beam was focused to a spot size of $35 \times 35 \mathrm{~nm}$ using a Fresnel Zone plate. The pixel size used in the carbon K-edge STXM image sets was $35 \mathrm{~nm}$.

In a second set of STXM experiments, ex-situ aluminum K-edge measurements were done at beamline 10.ID.1 of the Canadian Light Source (CLS, Saskatoon, Canada) using a $35 \mathrm{~nm}$ zone plate. In every case, the samples were placed on silicon nitride windows (100 nm thickness) and mounted perpendicular to the beam on a piezoelectric stage. The aluminum stacks were recorded in the $1555-1590 \mathrm{eV}$ range with an energy resolution of $0.15 \mathrm{eV}$ and a spatial resolution of $70 \mathrm{~nm}$. Aluminum reference compounds were measured performing a line scan along the samples with a dwell time of $4 \mathrm{~ms}$ and an energy resolution of $0.15 \mathrm{eV}$. Normalization and background correction was done subtracting to every spectrum a second spectrum obtained from an aluminum-free region. The aluminum K-edge X-ray absorption spectra (XAS) of these reference compounds were used to perform a least squares linear combination fitting of the aluminum stacks obtained from both H-ZSM-5-C and H-ZSM-5-500. The STXM data files were analyzed using aXis2000 software.

In a third set of STXM experiments, pyridine adsorption experiments were performed on the interferometrically controlled microscope at beamline 11.0 .2 of the Advanced Light Source (ALS) at the Lawrence Berkeley National Laboratory (LBNL, Berkeley, USA) [9]. Prior to pyridine adsorption, $20 \mathrm{mg}$ of zeolite sample was heated $\left(170^{\circ} \mathrm{C}\right)$ in a round-bottom flask under vacuum $\left(10^{-3}\right.$ mbar) for $60 \mathrm{~min}$. Subsequently, the samples were prepared adding $0.2 \mu \mathrm{l}$ of pyridine (Acros Organics, 99\%). After a waiting time of $60 \mathrm{~min}$, pyridine was partially removed by heating the samples at $400{ }^{\circ} \mathrm{C}$ for a period of $60 \mathrm{~min}$. During the STXM experiments, the samples were placed on silicon nitride windows (100 nm thickness) and mounted perpendicular to the beam on a piezoelectric stage. The monochromatized X-ray beam was focused to a spot size of $25 \times 25 \mathrm{~nm}$ using a Fresnel zone plate. The absorption at the carbon K-edge was measured in the range of $280-310 \mathrm{eV}$ collecting a series of stacks with an energy resolution of $0.2 \mathrm{eV}$. After spatially aligning the stack, PCA was used to obtain the primary components in the data set. Subsequently, a cluster analysis was performed to classify pixels according to statistical similarities in their spectra. The pixel size used in the image sets was $30 \mathrm{~nm}$.

\subsection{Temperature-Programmed Desorption}

Temperature-Programmed Desorption (TPD) measurements with ammonia as probe molecule were performed using a Micromeritics AutoChemII 2920 apparatus. The sample, $0.15 \mathrm{~g}$ in both cases, was first pretreated in helium $(25 \mathrm{ml} / \mathrm{min})$ for $30 \mathrm{~min}$ at $600{ }^{\circ} \mathrm{C}$, then cooled down to $100{ }^{\circ} \mathrm{C}$, and saturated with ammonia to its equilibrium state. Prior to desorption, samples were flushed in helium for $30 \mathrm{~min}$. Subsequently, ammonia desorption was performed in the range of $100-600^{\circ} \mathrm{C}$ at a heating rate of $10^{\circ} \mathrm{C} / \mathrm{min}$.

\subsection{Sputter depth profiling X-ray Photoelectron Spectroscopy}

Sputter depth profiling X-ray Photoelectron Spectroscopy (XPS) measurements were performed on a Physical Electronics Quantum 2000 Scanning X-ray Photoelectron Spectrometer or a Physical Electronics Quantera X-ray photoelectron spectrometer. In either instrument, the base pressure was kept $\sim 1 \times 10^{-9}$ mbar. The XPS spectra were collected using monochromatic aluminum $\mathrm{K} \alpha$ radiation $(1486.6 \mathrm{eV})$. Charging was neutralized using the combined low energy electron flood gun and low energy argon ion gun of the instrument. Survey scans were collected using a pass energy of $187 \mathrm{eV}$ and region scans with a pass energy of $58 \mathrm{eV}$. For typical measurements, H-ZSM-5 zeolites were deposited onto a vitreous 
carbon substrate to ensure dispersion. A nominal $5 \mu \mathrm{m}$ or $10 \mu \mathrm{m}$ $\mathrm{X}$-ray beam was used for the analysis. The depth calibration for the sputter depth profiling was determined from the time required to sputter through a known thickness of $\mathrm{SiO}_{2}$ on a silicon wafer using the same ion gun settings. In this manner, the depths of H-ZSM-5-C and H-ZSM-5-500 were estimated. The Si/Al atomic ratios were calculated using the integrated peak areas of the Si2p and Al2p making use of an integrated Physical Electronics data analysis software (Multipak).

\section{8. ${ }^{27}$ Al magic angle spinning nuclear magnetic resonance}

${ }^{27} \mathrm{Al}$ Magic Angle Spinning (MAS) Nuclear Magnetic Resonance (NMR) experiments were performed at $11.7 \mathrm{~T}$ on a Bruker Avance III spectrometer using a $3.2 \mathrm{~mm}$ triple resonance MAS probe head. The spectra were obtained at room temperature using $\pi / 12$ pulses at an rf-field of $94 \mathrm{kHz}, 10000$ scans and a recycle delay of $0.5 \mathrm{~s}$. The MAS rate was $20 \mathrm{kHz}$. The chemical shifts of ${ }^{27} \mathrm{Al}$ were externally referenced to $1 \mathrm{M}$ aluminum nitrate $\left(\mathrm{Al}\left(\mathrm{NO}_{3}\right)_{3}(\mathrm{aq})\right)$.

\section{Results and discussion}

\subsection{Performance changes by applying a mild hydrothermal treatment}

\subsubsection{Catalytic testing}

With the aim of assessing the influence that a mild steaming treatment has on the MTH performance of zeolite H-ZSM-5 catalyst powders, H-ZSM-5-C and H-ZSM-5-500 were tested under realistic MTH conditions at $350{ }^{\circ} \mathrm{C}$. The catalytic performances of both zeolite H-ZSM-5 samples are compared in Fig. 1.

It can be observed from Fig. 1 that H-ZSM-5-C showed full methanol conversion in the beginning of the MTH reaction, whereas H-ZSM-5-500 presented an initial methanol conversion of $\sim 92 \%$. With increasing time-on-stream, the catalytic activity progressively dropped, revealing important differences between both samples. Most notably, the higher methanol conversion observed for H-ZSM-5-500 for a larger time-on-stream is indicative for its higher resistance toward deactivation. After $35 \mathrm{~h}$ on stream, H-ZSM-5-C was fully deactivated, while H-ZSM-5-500 presented a methanol conversion above 55\%. A lower intrinsic activity and improved resistance toward deactivation are consistent with a reduction in the density of acid sites [10]. It may be noted, however, that the deactivation behavior of zeolite catalysts is a complex issue. Among material parameters, topology, crystal size, defects as well as density, and strength of Brønsted acid sites have all been proposed in the literature as relevant parameters for deactivation during the MTH reaction $[3,11]$. Nonetheless, for series of catalysts prepared by dealumination, the improved stability has been linked primarily to the lower density of acid sites, as previously demonstrated for H-beta [12] and H-ZSM-5 [13]. This is caused primarily due to a reduced tendency toward secondary and coke-forming reactions when having a lower acid site density $[10,14]$. In contrast to the observed activity differences, the selectivity of H-ZSM-5-C was very similar to that of $\mathrm{H}-\mathrm{ZSM}-5-500$. More in particular, as shown in Fig. 1b and c, for both zeolite H-ZSM-5 powders, the same compounds, in similar concentrations, were observed in the effluent.

Additional measurements of the hydrocarbon species retained in the catalyst materials after MTH reaction disclosed important variations between H-ZSM-5-C and H-ZSM-5-500. As shown in Fig. 2, H-ZSM-5-C contained a mixture of methylbenzenes (tetraMBs $\sim$ pentaMB $\gg$ hexaMB) and poly-aromatic species. In contrast, H-ZSM-5-500 possessed a different amount of methylbenzenes (tetraMBs > pentaMB $\gg$ hexaMB) and the absence of poly-aromatic species after MTH reaction. Methylbenzenes are typically the major group of compounds in the material retained within the pores of H-ZSM- 5 catalysts after the MTH reaction, in particular for samples with relatively low Al contents [15]. Thus, it appears likely that the unusually high concentration of heavier species found in the extract from the H-ZSM-5-C catalyst is related to the fairly low $\mathrm{Si} / \mathrm{Al}$ ratio. The fact that comparatively very little
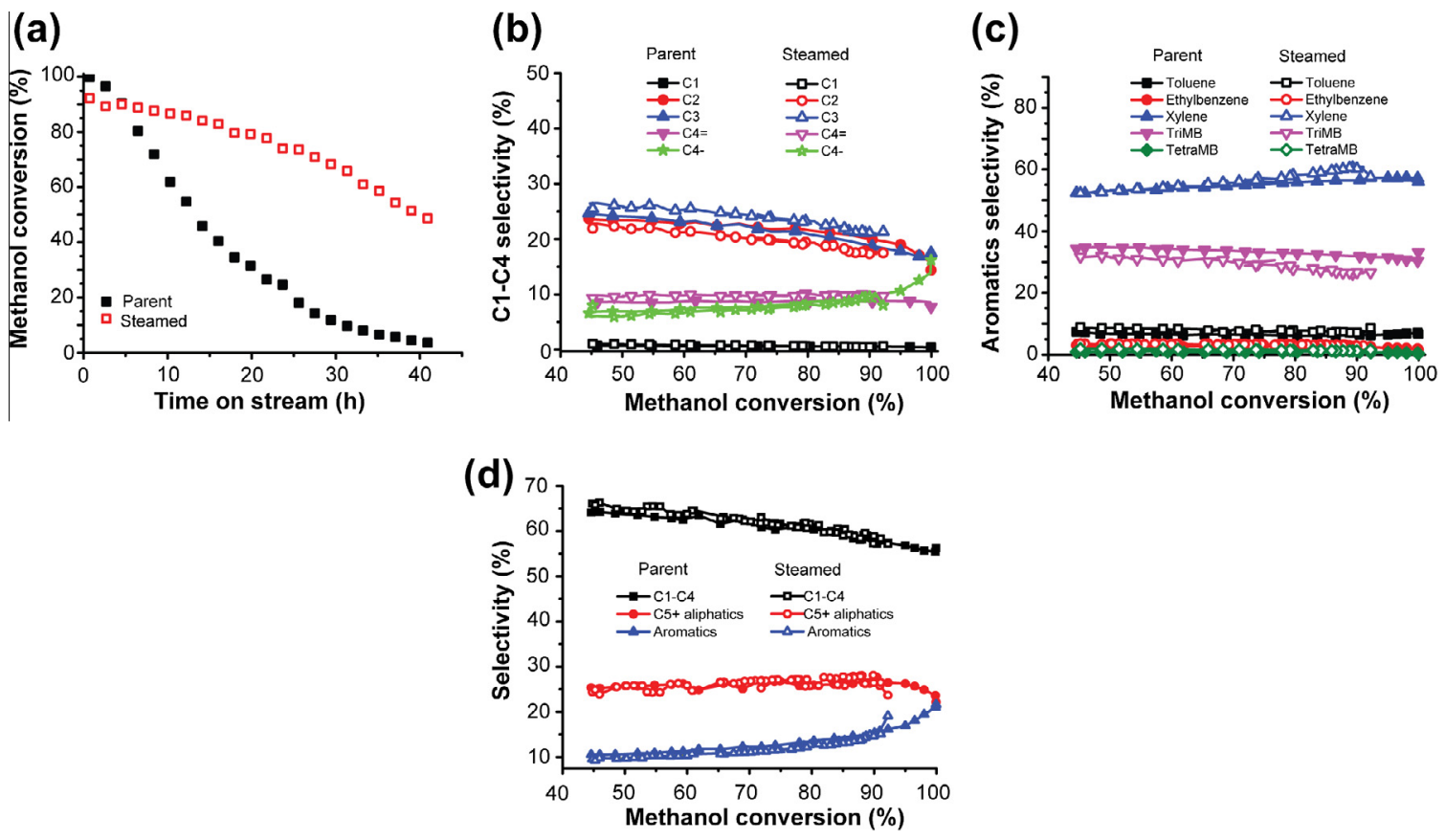

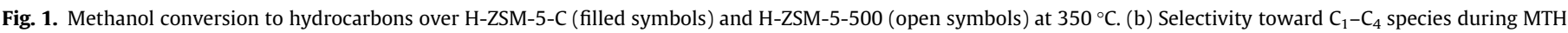

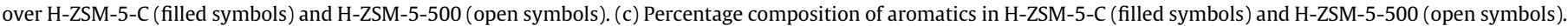
(d) Selectivity toward $\mathrm{C}_{1}-\mathrm{C}_{4}, \mathrm{C}_{5+}$ aliphatic and aromatic species during MTH over H-ZSM-5-C (filled symbols) and H-ZSM-5-500 (open symbols). 

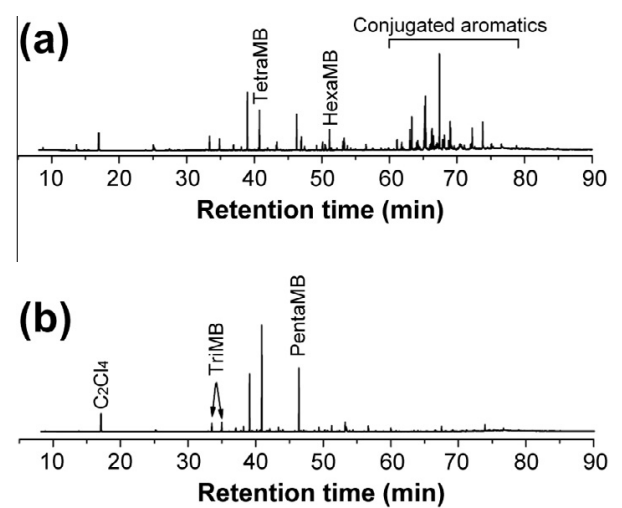

Fig. 2. Retained hydrocarbon species in H-ZSM-5-C (a) and H-ZSM-5-500 (b) after performing the MTH reaction at $350^{\circ} \mathrm{C}$.

poly-aromatic compounds are found in the extract of the H-ZSM-5500 catalyst might be attributed to several reasons. One could speculate that the mesopores formed upon steaming contain very few acid sites, or conversely, that the coke potentially formed in these mesopores quickly grows into species insoluble in $\mathrm{CH}_{2} \mathrm{Cl}_{2}$ and thus undetectable by the dissolution/extraction protocol [16]. However, as is demonstrated by the ammonia TPD, discussed below, the density of acid sites is lower for the H-ZSM-5-500, and this is inherently linked to a reduced coking rate and tendency for aromatics formation.

\subsection{Physicochemical changes by applying a mild hydrothermal treatment}

A series of bulk, surface, and local characterization techniques have been applied to gain detailed insight into the physicochemical properties of H-ZSM-5-C and H-ZSM-5-500.

\subsection{Nitrogen physisorption and X-ray diffraction}

As described in a previous publication [17], H-ZSM-5-C is composed of rectangular parallelepiped shape crystals domains, having dimensions of $200-800 \mathrm{~nm}$. The agglomeration of these domains results into the formation of $1-2 \mu \mathrm{m}$ spheroid particles. Accordingly, the nitrogen adsorption and desorption isotherms obtained for H-ZSM-5-C were characteristic of $\mathrm{H}-\mathrm{ZSM}-5$ spheroid aggregates composed by smaller individual particles [18]. This is illustrated in Fig. S1 of the Supporting information. In contrast, the isotherms obtained for H-ZSM-5-500 showed a modification in the hysteresis cycle appearing at high partial pressures (between 0.5 and $0.9 \mathrm{P} /$ $\mathrm{Po})$ with respect to the isotherms of H-ZSM-5-C. The more pronounced hysteresis cycle is indicative of the generation of mesoporosity. Importantly, however, the XRD patterns of H-ZSM-5-C and H-ZSM-5-500, shown in Fig. S2 of the Supporting information, revealed that after applying a mild hydrothermal treatment, the overall zeolite H-ZSM-5 structure was maintained.

\subsection{Magic angle spinning nuclear magnetic resonance}

To obtain information on the coordination changes in aluminum taking place by applying a mild hydrothermal treatment, ${ }^{27}$ Al MAS NMR spectroscopy was performed on H-ZSM-5-C and H-ZSM-5-500. As depicted in Fig. 3, the NMR spectrum of $\mathrm{H}-$ ZSM-5-C displays peaks that can be directly attributed to 4- and 6-fold aluminum, located in the region of 60-50 [19-21] and $0 \mathrm{ppm}$ [19-21], respectively. In the case of H-ZSM-5-500, the NMR spectrum shows an increase in the amount of 6-fold aluminum at the expense of 4 -fold aluminum species. Additionally, a

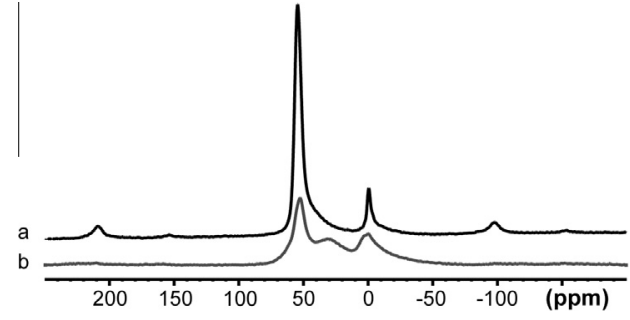

Fig. 3. ${ }^{27} \mathrm{Al}$ Magic Angle Spinning (MAS) Nuclear Magnetic Resonance (NMR) spectra of H-ZSM-5-C (a) and H-ZSM-5-500 (b).

resonance in the region of $30-35 \mathrm{ppm}$, attributed to 5-fold aluminum species, was found after steaming [22].

The quantification of the ${ }^{27} \mathrm{Al}$ MAS NMR spectra obtained from H-ZSM-5-C revealed that $87 \%, 1 \%$, and $12 \%$ of the aluminum show 4-fold, 5-fold, and 6-fold coordination environments, respectively. In contrast, the concentration of 4-fold, 5-fold, and 6-fold aluminum obtained from the ${ }^{27} \mathrm{Al}$ MAS NMR spectra of H-ZSM-5-500 was $38 \%, 48 \%$, and $14 \%$, respectively. Consequently, these findings reveal a relative increase in the amount of 5- and 6-fold coordinated aluminum after performing a mild hydrothermal treatment.

\subsection{Temperature-programmed desorption}

To investigate the influence that a mild hydrothermal treatment has on the acidic properties of zeolite H-ZSM-5 powders, temperature-programmed desorption experiments were performed with ammonia as probe molecule.

As depicted in Fig. 4, a decrease in the overall acidity (i.e., the total area below the curves) was found after a mild steaming treatment. More specifically, the total ammonia desorption recorded from the TPD experiments was $51.9 \mathrm{ml}$ (STP)/g and $27.5 \mathrm{ml}$ (STP)/g for the calcined and steamed catalyst sample, respectively. Furthermore, the intensity reduction as well as shift of the desorption peak appearing at higher temperatures is indicative of a loss of strong acid sites. Accordingly, ammonia TPD informs that steaming has a significant impact on the acidic properties of H-ZSM-5-500.

\subsection{X-ray photoelectron spectroscopy}

To investigate a possible interplay between the above-mentioned physicochemical variations and the amount of aluminum in the near surface region of the zeolite $\mathrm{H}-\mathrm{ZSM}-5$ powders, XPS sputter depth profiling measurements were performed on $\mathrm{H}$ ZSM-5-C and H-ZSM-5-500. To this end, the amount of silicon and aluminum was measured over the first $100 \mathrm{~nm}$ from the zeolite surface.

The results of the XPS analysis are summarized in Fig. 5 and show a substantial decrease in the $\mathrm{Si} / \mathrm{Al}$ ratio after applying a mild hydrothermal treatment. Most notably, the average $\mathrm{Si} / \mathrm{Al}$ ratio over

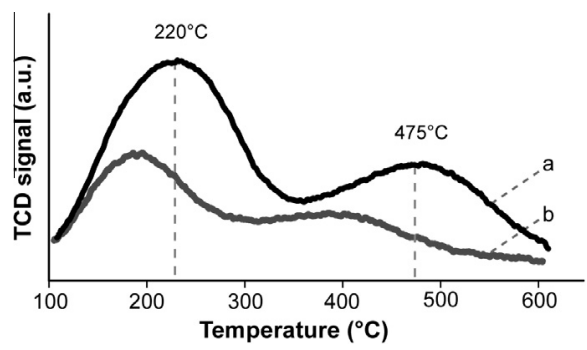

Fig. 4. Ammonia-Temperature-Programmed Desorption (TPD) curves of H-ZSM-5C (a) and H-ZSM-5-500 (b). 
the first $\sim 100 \mathrm{~nm}$ decreased from 10.4 for H-ZSM-5-C to 8.2 for $\mathrm{H}-$ ZSM-5-500. This observation indicates a surface re-alumination after the mild hydrothermal treatment applied. This re-alumination is most probably due to the mobility of the generated extraframework aluminum species.

\section{Nanoscale imaging of aluminum, carbon deposits and acidity}

In order to investigate in more detail, the differences in performance and physicochemical properties between $\mathrm{H}-\mathrm{ZSM}-5-\mathrm{C}$ and H-ZSM-5-500 STXM have been used to generate chemical maps of aluminum, carbon deposits, and acidity, the latter indirectly by using pyridine as probe molecule. The results of these three sets of advanced STXM experiments are described below.

\subsection{Scanning transmission X-ray microscopy of the state of aluminum upon steaming}

Complementary to the ${ }^{27} \mathrm{Al}$ MAS NMR data described above, STXM was applied to gain further insight into the modifications taking place in the state of aluminum within zeolite H-ZSM-5 catalyst powders. As shown in a recent publication [17], this can be performed by measuring the absorption at the aluminum K-edge in combination with a set of 4-, 5-, and 6-fold oxygen coordinated aluminum-containing minerals. To this end, the state of aluminum was characterized acquiring aluminum stacks of H-ZSM-5-C and H-ZSM-5-500. Subsequently, a stack fitting was performed with a set of aluminum reference compounds, namely albite (4-fold $\mathrm{O}$ coordinated aluminum mineral), berlinite (4-fold O-coordinated aluminum mineral), and andalusite (mineral with 5- and 6-fold O-coordinated aluminum).

The results obtained for H-ZSM-5-C, presented in a recent publication [17], showed that this sample mainly contained 4-fold coordinated aluminum next to minor amounts of higher aluminum coordination environments. More specifically, the spectral fitting revealed a $92 \%$ and $8 \%$ contribution of albite and andalusite reference compounds, respectively, as well as the lack of contribution from berlinite. In contrast, as shown in Fig. 6, a mild hydrothermal treatment induces an increase in the relative coordination environment of aluminum, being in line with the ${ }^{27} \mathrm{Al}$ MAS NMR data. In other words, the contribution of andalusite increased to $60 \%$, while that of albite aluminum reference compound decreased to $20 \%$. In addition to the coordination change taking place upon steaming, the $20 \%$ contribution of berlinite in the spectral fitting provides experimental evidence for a modification in the local aluminum environment without varying its coordination number. In this context, previous studies have reported the presence of different 4-fold coordinated aluminum species after steaming, arising from

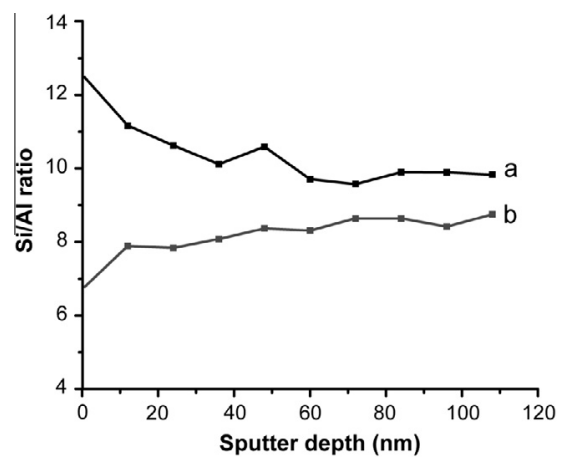

Fig. 5. X-ray Photoelectron Spectroscopy (XPS) sputter depth profile plot showing the Si/Al ratio as a function of the sputter depth for H-ZSM-5-C (a) and H-ZSM-5500 (b). the generation of tetrahedrally coordinated extra-framework aluminum $\left(\mathrm{EFAL}^{\mathrm{IV}}\right)$ species [23-25]. These aluminum species have a peak in the ${ }^{27} \mathrm{Al}$ MAS NMR spectra at around $53 \mathrm{ppm}$ and as such they cannot be easily distinguished from the framework aluminum (FAL) species in the above described NMR experiments.

\subsection{In situ scanning transmission X-ray microscopy of carbon deposits during MTH}

To address the question of how the differences observed in the catalytic performances of H-ZSM-5-C and H-ZSM-5-500 are related to nanoscopic phenomena taking place at the level of a single zeolite aggregate, a MEMS nanoreactor was applied in combination with STXM [26]. In this way, it has been possible to measure the absorption at the carbon K-edge for H-ZSM-5-C and H-ZSM-5500 during $\mathrm{MTH}$ at $350^{\circ} \mathrm{C}$.

Thanks to the narrow energy width and chemical sensitivity of the transitions appearing in the carbon K-edge XAS, the comparison of the spectral features offers a way to elucidate differences in the nature of the hydrocarbon species formed during MTH reaction. More specifically, among the features present in the carbon XAS, those appearing at $285 \mathrm{eV}, 287.6-288.2 \mathrm{eV}$, and $291-293.5 \mathrm{eV}$ are of particular interest for the MTH reaction as they correspond, respectively, to transitions from the carbon $1 \mathrm{~s}$ to the unoccupied $\mathrm{C}=\mathrm{C} \pi^{*}$ [27-31], $\mathrm{C}-\mathrm{H} \sigma^{*}[30-32]$, and C $-\mathrm{C} \sigma^{*}[33,34]$ molecular orbitals. It should be noted, however, that in the present study, we have limited our analysis to the spectral region going from $283 \mathrm{eV}$ up to $287 \mathrm{eV}$ due to the significant mixing and degeneration of some of the transitions appearing at higher energies in the carbon K-edge XAS.

In Fig. 7a and b, the carbon K-edge XAS obtained in the early stage of the MTH reaction (60-120 min) from the external regions of the zeolite H-ZSM-5-C and H-ZSM-5-500 aggregates, respectively, are presented. Overall, both XAS displayed different shapes, being indicative of different catalytic reactions taking place at the external regions of the zeolite H-ZSM-5 powders. Among the different transitions present in the spectra, it is noteworthy to mention the broadening of the $285 \mathrm{eV}$ peak in the carbon X-ray absorption spectrum of $\mathrm{H}-\mathrm{ZSM}-5-\mathrm{C}$, which is related to the presence of non-equivalent carbon atoms [35]. Importantly, these transitions can be used as a fingerprint of coke precursor species in the carbon K-edge XAS since they originate from aromatic species with high symmetry. To support this hypothesis, the carbon XAS of a select series of reference compounds containing different amounts of non-equivalent carbon atoms are presented in Fig. 8. From this figure, it is suggested that the broadening of the $285 \mathrm{eV}$ peak can be attributed to the presence of coke precursor species, such as naphthalene and/or anthracene.

In the later stage of the MTH reaction (280-340 min), the peak previously present at $285 \mathrm{eV}$ splits in several transitions in the carbon X-ray absorption spectrum of H-ZSM-5-C. This observation indicates a significant increase in the amount of non-equivalent carbon atoms, which can be attributed to the formation of coke precursor species. In contrast, the carbon X-ray absorption spectrum of H-ZSM-5-500 was similar to that obtained for shorter reaction times. In this case, the band located at $285 \mathrm{eV}$ did not alter its shape, indicating a limited formation of poly-aromatic species in the external regions of the zeolite H-ZSM-5-500 aggregate.

\subsection{Scanning transmission X-ray microscopy of Brønsted acidity changes upon steaming}

With the aim of elucidating the effect that a mild hydrothermal treatment has on the acidic properties of a zeolite H-ZSM-5 aggregate at the nanometer scale, pyridine adsorption experiments were performed in combination with STXM. In this manner, the existence 

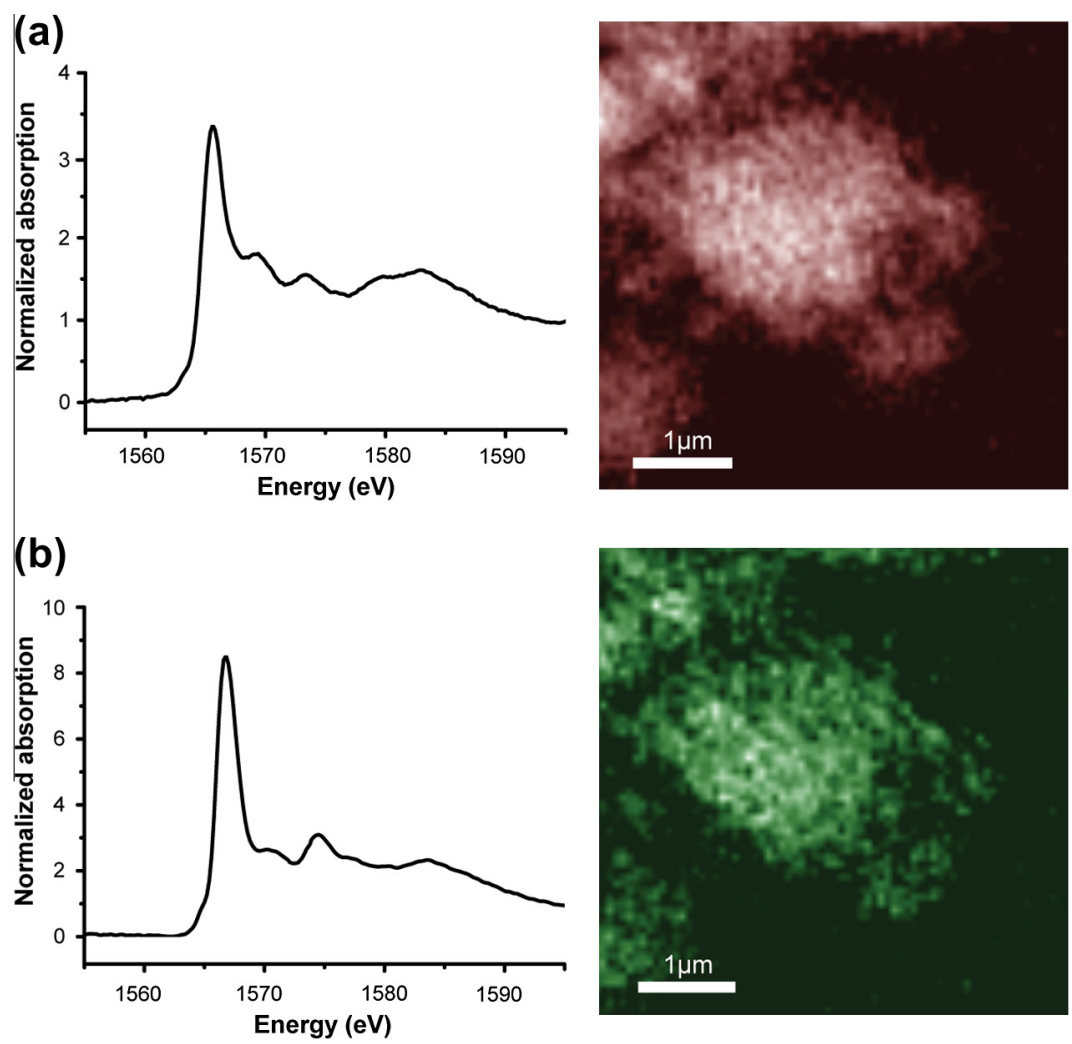

(c)
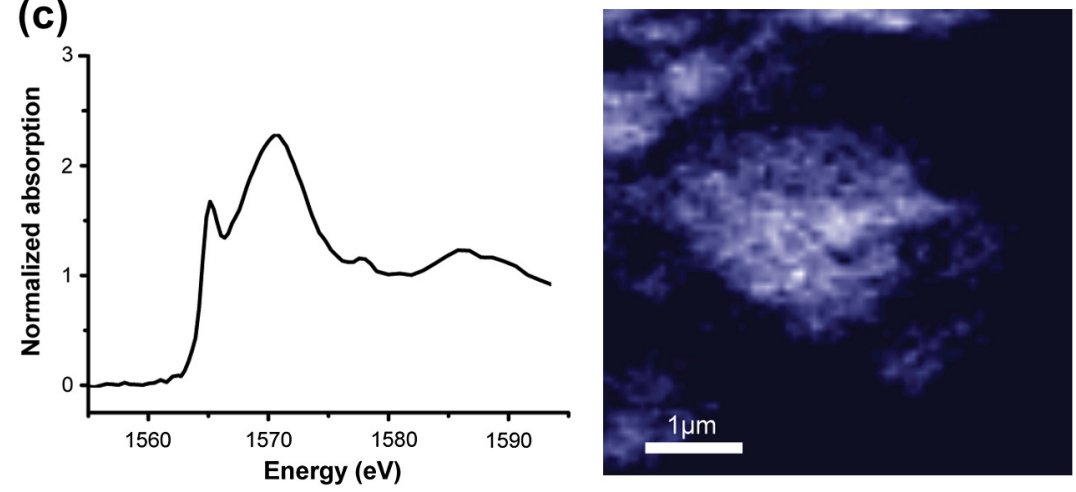

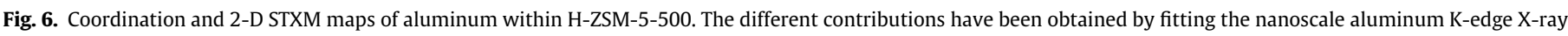

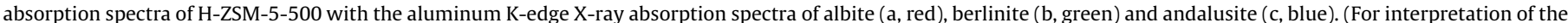
references to colour in this figure legend, the reader is referred to the web version of this article.)

of different degrees of pyridine interaction could be revealed by measuring the absorption at the carbon K-edge. Among the features present in the pyridine carbon K-edge X-ray absorption spectrum, those appearing at $285 \mathrm{eV}, 288 \mathrm{eV}$, and 291-293.5 eV correspond respectively to carbon $1 \mathrm{~s} \rightarrow \pi^{*}\left(\mathrm{e}_{2} \mathrm{u}\right), 1 \mathrm{~s} \rightarrow \pi^{*}\left(\mathrm{~b}_{2} \mathrm{~g}\right)$, and $1 \mathrm{~s} \rightarrow \sigma^{*}\left(\mathrm{e}_{2} \mathrm{~g}\right)$ transitions [36]. In contrast to the carbon X-ray absorption spectrum of benzene, the peak located at $285 \mathrm{eV}$ in the pyridine spectrum is divided into a "b1" and "a1" symmetry component due to the presence of nitrogen in the aromatic ring. The latter transitions are highly asymmetric as a result of vibrational effects, attributed to the different degrees of protonation of the pyridine molecule [37]. In other words, a strong protonation can bend the pyridine molecule further splitting the $\pi^{*}\left(\mathrm{e}_{2} \mathrm{u}\right)$ transitions. On this basis, a more pronounced broadening of the carbon spectral shape in the range going from $284 \mathrm{eV}$ up to $287 \mathrm{eV}$ can be explained by a wider variety of pyridine-acid site interactions.

The results for $\mathrm{H}-\mathrm{ZSM}-5-\mathrm{C}$, obtained from the analysis performed after pyridine desorption at $400{ }^{\circ} \mathrm{C}$, are summarized in
Fig. 9a. The data reveal the existence of carbon K-edge XAS originating from the external and internal regions of the zeolite $\mathrm{H}$ ZSM-5-C aggregate. Both carbon K-edge XAS displayed a similar shape although that originating from the external regions of the aggregate showed a slightly higher intensity in the transitions located at around $286.4 \mathrm{eV}$.

Fig. 9b shows the STXM data for H-ZSM-5-500, revealing the existence of different carbon K-edge XAS spectra arising from the internal and external regions of the zeolite aggregate. Both carbon K-edge XAS displayed a reduction in the broadening of the peak appearing in the range going from $284 \mathrm{eV}$ up to $287 \mathrm{eV}$ when compared with the spectra of $\mathrm{H}-\mathrm{ZSM}-5-\mathrm{C}$. This indicates that there are a smaller number of different pyridine-acid site interactions in H-ZSM-5-500 after exposing this sample to pyridine. However, the differences between the carbon K-edge XAS collected from the internal and external aggregate regions are more pronounced than those observed for H-ZSM-5-C. In particular, the comparison of the features appearing in both carbon K-edge XAS revealed a 
(a)

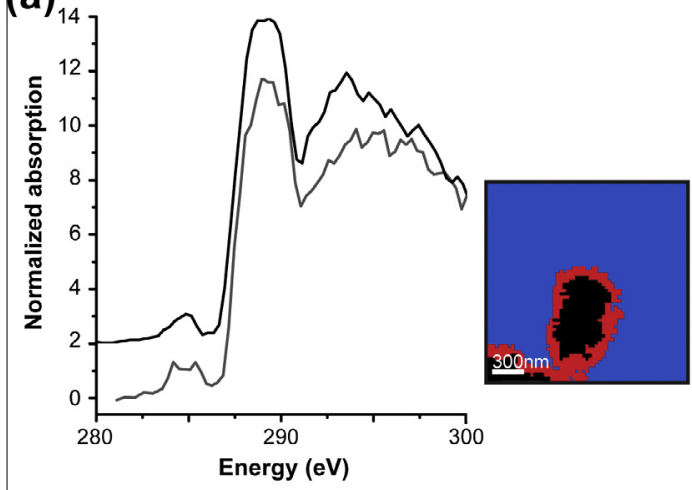

(b)

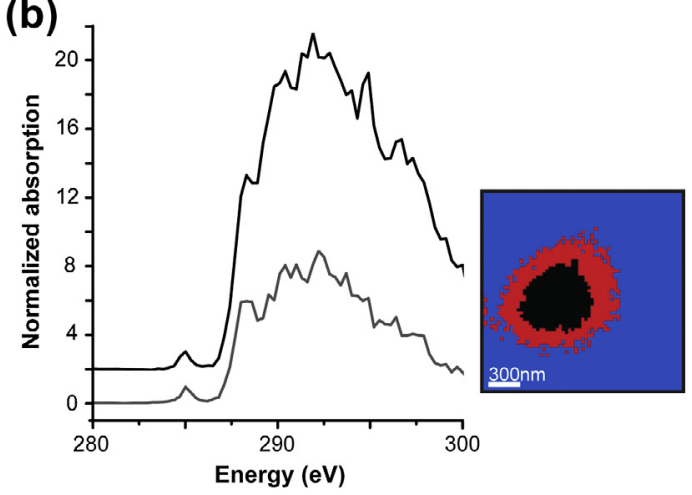

Fig. 7. Carbon K-edge X-ray absorption spectra obtained during the course of the MTH reaction at $350{ }^{\circ} \mathrm{C}$ over H-ZSM-5-C (a) and H-ZSM-5-500 (b). Spectra are presented in black and gray for the period of 60-120 min and $280-340 \mathrm{~min}$, respectively. The inserts of every image show the cluster analysis index. In every case, the X-ray absorption spectra were obtained from the regions depicted in red in the cluster index. All the spectra have been normalized to the transition located at $285 \mathrm{eV}$. (For interpretation of the references to colour in this figure legend, the reader is referred to the web version of this article.)

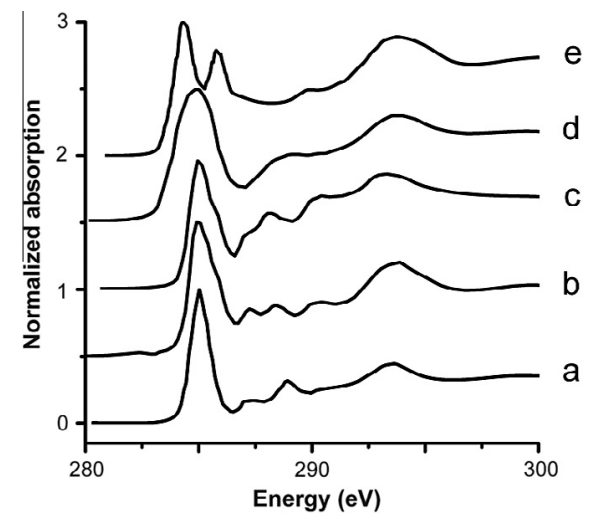

Fig. 8. Carbon K-edge X-ray absorption reference spectra of benzene (a), naphthalene (b), tetramethylnaphthalene (c), pyridine (d), and anthracene (e). The reference spectra have been digitalized from Hitchcock's group gas phase core excitation database (http://unicorn.mcmaster.ca/).

more pronounced broadening of the carbon $1 \mathrm{~s} \rightarrow \pi^{*}\left(\mathrm{e}_{2} \mathrm{u}\right)$ transitions in the internal regions of the zeolite $\mathrm{H}-\mathrm{ZSM}-5-500$ aggregate. In line with the previous reasoning, the existence of carbon $1 \mathrm{~s} \rightarrow \pi^{*}\left(\mathrm{e}_{2} \mathrm{u}\right)$ transitions spread over a higher energy range in the pyridine carbon K-edge XAS can be related to the presence of a wider variety of interactions between pyridine and the acid sites located in the internal regions of the zeolite H-ZSM-5 aggregate. Accordingly, the latter observation suggests that after applying a mild hydrother-
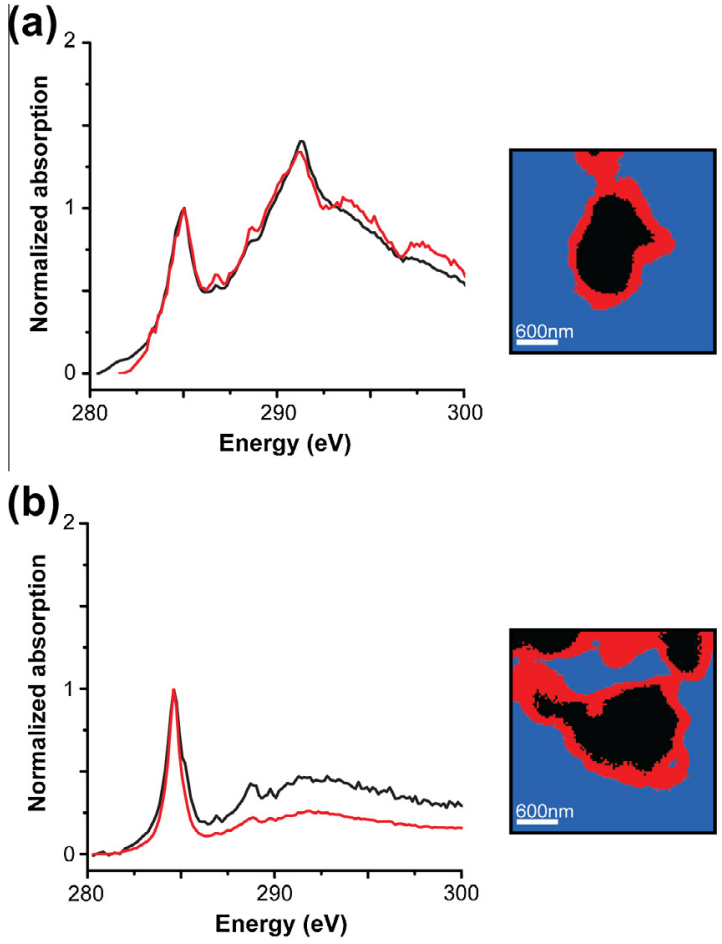

Fig. 9. Carbon K-edge X-ray absorption spectra of H-ZSM-5-C (a) and H-ZSM-5-500 (b) with adsorbed pyridine after desorption at $400{ }^{\circ} \mathrm{C}$. The insets of every image show the cluster analysis index. The colored regions in the cluster index correspond to the regions of the zeolite H-ZSM-5 aggregate from which the spectra with the same color coding were obtained. (For interpretation of the references to colour in this figure legend, the reader is referred to the web version of this article.)

mal treatment the core of the zeolite H-ZSM-5 aggregate somehow preserves its acidic properties to a higher extent as compared to the outer rim regions. In other words, STXM suggests the presence of an egg-yolk distribution of acidity for H-ZSM-5-500.

\section{Interplay between bulk performance, physicochemical properties, nanoscale reactivity and chemical imaging}

When considering the ensemble of data collected in this contribution, it is interesting to note that several material parameters have been modified as a result of steaming, in particular the mesopore volume and acid site density. As expected, the lower density of acid sites in H-ZSM-5-500 was observed to correlate with a lower catalyst activity during conventional catalytic testing (Fig. 1a). However, the effluent selectivity of the H-ZSM-5-C and H-ZSM-5-500 samples was very similar, and the expected decrease in aromatics selectivity with a decrease in acid site density was not observed (Fig. 1b-d). This observation suggests that the change in acid site density observed by $\mathrm{NH}_{3}$ TPD and XPS analysis of the parent and steamed samples (Figs. 4 and 5) is not sufficient to alter the relative rates of the various hydrocarbon pool reactions leading to effluent product formation (i.e., methylation vs. cracking vs. aromatization vs. dealkylation). Even so, the parent sample, H-ZSM5-C, deactivated faster than the steamed sample, H-ZSM-5-500 (Fig. 1a). Furthermore, analysis of retained hydrocarbons in the samples after testing revealed that more poly-aromatic molecules were deposited in the parent sample compared to the steamed sample, at the end of the test (Fig. 2). With reference to the open literature, the difference could be ascribed to a shorter diffusion path in the steamed sample compared to the parent sample, and as such, a shorter residence time of aromatic products in the crystal pores before diffusing out into the gas phase. 


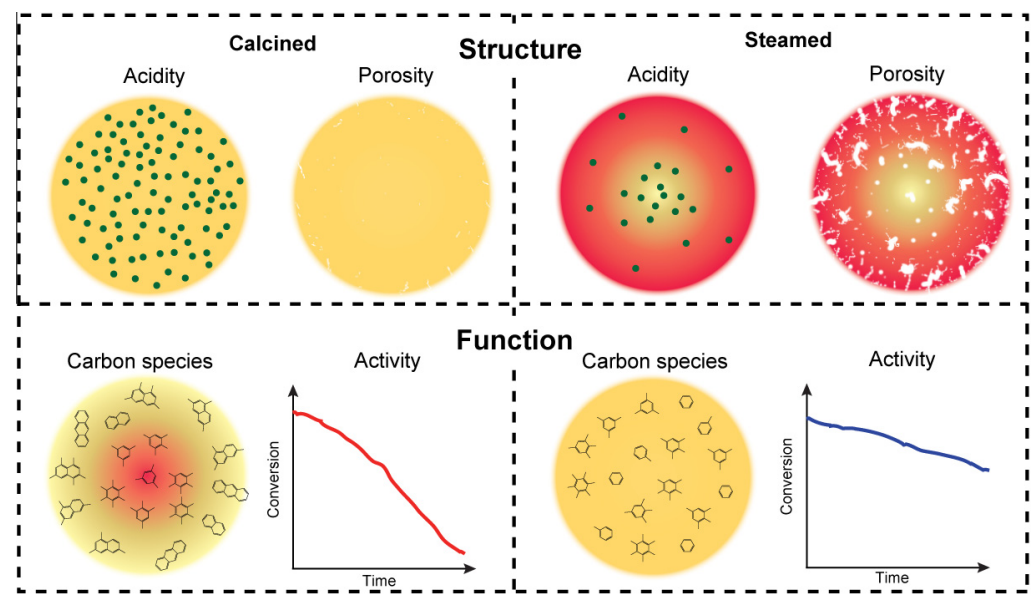

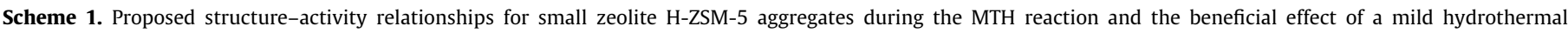
treatment on the overall catalyst stability.

It should, however, be clear that there still exists a discrepancy between the two characterization approaches described, i.e., nanoscale reactivity and chemical imaging vs. bulk performance and physicochemical characterization. Indeed, as the methanol-tohydrocarbons reaction is a sequential process, a detailed analysis of the active catalyst materials becomes far from trivial as the state of the catalyst material at the top of the bed will be different from the state of the catalyst material at the bottom. As the catalytic reactor for the bulk activity measurements substantially differs in e.g. dimensions and geometry from the employed nano-spectroscopic reaction cell [17], it is not possible to trustfully link both sets of data. Future experiments have therefore to focus on the proper isolation of individual catalyst particles from different bed heights and subsequent micro-spectroscopic analysis of the coke deposits and acidity at the single particle level with STXM. Preferably, these sets of experiments have then to be conducted at different reaction temperatures and partial pressures as well as varying gas velocities.

\section{Conclusions}

The effect of a mild hydrothermal treatment on the activity, selectivity, and stability of zeolite $\mathrm{H}-\mathrm{ZSM}-5$ catalyst powders has been investigated during the $\mathrm{MTH}$ reaction at $350^{\circ} \mathrm{C}$. Small differences in the activity and selectivity have been revealed at the initial stages of the reaction between a calcined (i.e., $\mathrm{H}-$ ZSM-5-C) and steamed (i.e., H-ZSM-5-500) sample. At longer times on stream, however, H-ZSM-5-C showed a lower resistance toward deactivation compared to H-ZSM-5-500. The main difference in the catalytic performance of both samples arises from the production of poly-aromatic species in the outer regions of the zeolite H-ZSM-5-C aggregate, as observed with in situ carbon K-edge STXM. The presence of poly-aromatics in the external catalyst regions obviously hinders the transport properties of the reacting molecules, in particular methanol, ultimately leading to severe diffusion limitations in the MTH process [38]. In contrast, the reduced formation of poly-aromatic species within the zeolite H-ZSM-5-500 aggregate preserves its reactant accessibility toward the acid sites, which has a positive impact on the overall MTH stability of the catalyst material.

Alternatively, it has been shown with aluminum K-edge STXM and ${ }^{27} \mathrm{Al}$ MAS NMR that steaming has an impact on the state of aluminum, inducing modifications in its coordination as well as in its local environment. These changes result in the loss of a considerable number of acid sites and a re-alumination of the zeolite H-ZSM-5 aggregate's surface, as revealed by ammonia TPD and XPS. STXM at the carbon K-edge on both zeolite H-ZSM-5 powders after pyridine adsorption revealed a more prominent reduction in the number and strength of the acid sites present in the outer rim of the zeolite aggregates upon steaming. In other words, the formation of poly-aromatic species during MTH goes hand in hand with the core-shell chemical maps of acidity before steaming.

Scheme 1 summarizes our current ideas related to the improved MTH stability of zeolite H-ZSM-5 powders after applying a mild hydrothermal treatment. We propose that a lower number and strength of acid sites present in the outer rim of the zeolite aggregates in combination with the increased mesoporosity translate into shorter residence time of aromatic products in the pores before diffusing out into the gas phase. As a result, there is a decrease in the amount of undesired chemical transformations taking place within the H-ZSM-5-500 sample, which reduces the formation of poly-aromatic compounds. In other words, a lower production of poly-aromatic species at the outer rim of the mildly steamed zeolites together with the formation of mesoporosity reasonably preserves the diffusion properties of the reacting and generated molecules, explaining the differences observed in the catalyst stability between of $\mathrm{H}-\mathrm{ZSM}-5-\mathrm{C}$ and $\mathrm{H}-\mathrm{ZSM}-5-500$.

\section{Acknowledgments}

Dr. B. Watts and Dr. J. Raabe (both from the Swiss Light Source, Switzerland), Dr. T. Tyliszczak and Dr. A.L.D. Kilcoyne (both from the Lawrence Berkeley National Laboratory, USA) as well as Dr. P.S. Miedema (Utrecht University, The Netherlands) are kindly thanked for their contributions and fruitful discussions. K. Cats and $\mathrm{H}$. van der Bij (both from Utrecht University, The Netherlands) are thanked for their help during STXM experiments. We thank NRSC-C (BMW), NWO-CW Top (BMW) and NWO-CW VICI (FMFdG) for financial support. S.T.'s Ph.D. grant is financed by inGAP, which receives funding from the Norwegian Research Council under Contract Number 174873.

\section{Appendix A. Supplementary material}

Supplementary data associated with this article can be found, in the online version, at http://dx.doi.org/10.1016/j.jcat.2013.07.009. 


\section{References}

[1] A.Y. Khodakov, W. Chu, P. Fongarland, Chem. Rev. 107 (2007) 1692.

[2] T. Mokrani, M. Scurrell, Catal. Rev. Sci. Eng. 51 (2009) 1.

[3] M. Bjørgen, F. Joensen, K.P. Lillerud, U. Olsbye, S. Svelle, Catal. Today 142 (2009) 90;

U. Olsbye, S. Svelle, M. Bjorgen, P. Beato, T.V.W. Janssens, F. Joensen, S. Bordiga, K.P. Lillerud, Angew. Chem., Int. Ed. 51 (2012) 5810.

[4] M. Stocker, Microporous Mesoporous Mater. 29 (1999) 3;

K. Hemelsoet, J. Van der Mynsbrugge, K. De Wispelaere, M. Waroquier, V. Van Speybroeck, ChemPhysChem 14 (2013) 1526.

[5] C.D. Chang, A.J. Silvestry, ChemTech. 10 (1987) 624.

[6] P. Magnoux, H.S. Cerqueira, M. Guisnet, Appl. Catal. A-Gen. 235 (2002) 93.

[7] H.S. Cerqueira, G. Caeiro, L. Costa, F.R. Ribeiro, J. Mol. Catal. A-Chem. 292 (2008) 1 .

[8] J. Raabe, G. Tzvetkov, U. Flechsig, M. Boege, A. Jaggi, B. Sarafimov, M.G.C. Vernooij, T. Huthwelker, H. Ade, D. Kilcoyne, T. Tyliszczak, R.H. Fink, C. Quitmann, Rev. Sci. Instrum. 79 (2008) 113704.

[9] A.L.D. Kilcoyne, T. Tyliszczak, W.F. Steele, S. Fakra, P. Hitchcock, K. Franck, E. Anderson, B. Harteneck, E.G. Rightor, G.E. Mitchell, A.P. Hitchcock, L. Yang, T. Warwick, H. Ade, J. Synchrotron Radiat. 10 (2003) 125.

[10] M. Guisnet, P. Magnoux, Catal. Today 36 (1997) 477.

[11] K. Barbera, F. Bonino, S. Bordiga, T.V.W. Janssens, P. Beato, J. Catal. 280 (2011) 196.

[12] M. Bjørgen, S. Kolboe, Appl. Catal. A-Gen. 225 (2002) 285.

[13] S.M. Campbell, D.M. Bibby, J.M. Coddington, R.F. Howe, J. Catal. 161 (1996) 350

[14] A. de Lucas, P. Canizares, A. Durán, A. Carrero, Appl. Catal. A-Gen. 154 (1997) 221.

[15] M. Bjørgen, S. Svelle, F. Joensen, J. Nerlov, S. Kolboe, F. Bonino, L. Palumbo, S. Bordiga, U. Olsbye, J. Catal. 248 (2007) 195.

[16] F. Bleken, W. Skistad, K. Barbera, M. Kustova, S. Bordiga, P. Beato, K.P. Lillerud, S. Svelle, U. Olsbye, Phys. Chem. Chem. Phys. 13 (2011) 2539.

[17] L.R. Aramburo, E. de Smit, B. Arstad, M.M. van Schooneveld, L. Sommer, A Juhin, T. Yokosawa, H.W. Zandbergen, U. Olsbye, F.M.F. de Groot, B.M Weckhuysen, Angew. Chem., Int. Ed. 51 (2012) 3616;

L.R. Aramburo, J. Ruiz-Martinez, L. Sommer, B. Arstad, R. Buitrago-Sierra, A.
Sepulveda-Escribano, H.W. Zandbergen, U. Olsbye, F.M.F. de Groot, B.M. Weckhuysen, ChemCatChem 5 (2013) 1386.

[18] V. Mayagoitia, F. Rojas, I. Kornhauser, J. Chem. Soc. Faraday Trans. 81 (1985) 2931.

[19] S.M. Campbell, D.M. Bibby, J.M. Coddington, R.F. Howe, R.H. Meinhold, J. Catal. 161 (1996) 338.

[20] R. Jelinek, B.F. Chmelka, Y. Wu, P.J. Grandinetti, A. Pines, P.J. Barrie, J. Klinowski, J. Am. Chem. Soc. 113 (1991) 4097.

[21] S.M. Cabral de Menezes, Y.L. Lam, K. Damodaran, M. Pruski, Microporous Mesoporous Mater. 95 (2006) 286.

[22] J.X. Chen, T.H. Chen, N.J. Guan, J.Z. Wang, Catal. Today 93 (2004) 627.

[23] L. Yingcai, J. Mingyang, S. Yaojun, W. Tailiu, W. Liping, F. Lun, J. Chem. Soc. Faraday Trans. 92 (1996) 1647.

[24] B.H. Wouters, T. Chen, P.J. Grobet, J. Phys. Chem. B 105 (2001) 1135.

[25] A. Omegna, M. Haouas, A. Kogelbauer, R. Prins, Microporous Mesoporous Mater. 46 (2001) 177.

[26] J.F. Creemer, S. Helveg, G.H. Hoveling, S. Ullmann, A.M. Molenbroek, P.M. Sarro, H.W. Zandbergen, Ultramicroscopy 108 (2008) 993.

[27] S. Bernard, O. Beyssac, K. Benzerara, N. Findling, G. Tzvetkov, G.E. Brown, Carbon 48 (2010) 2506.

[28] E. Najafi, J.A. Wang, A.P. Hitchcock, J.W. Guan, S. Denommee, B. Simard, J. Am. Chem. Soc. 132 (2010) 9020.

[29] H.A. Katzman, P.M. Adams, T.D. Le, C.S. Hemminger, Carbon 32 (1994) 379.

[30] Y. Zubavichus, A. Shaporenko, V. Korolkov, M. Grunze, M. Zharnikov, J. Phys. Chem. B 112 (2008) 13711.

[31] P.R. Haberstroh, J.A. Brandes, Y. Gelinas, A.F. Dickens, S. Wirick, G. Cody, Geochim. Cosmochim. Acta 70 (2006) 1483.

[32] D. Solomon, J. Lehmann, J. Kinyangi, B. Liang, K. Heymann, L. Dathe, K. Hanley, S. Wirick, C. Jacobsen, Soil Sci. Soc. Am. J. 73 (2009) 1817.

[33] A.P. Hitchcock, I. Ishii, J. Elec, Spec. Rel. Phenom. 42 (1987) 11.

[34] A.P. Hitchcock, D.C. Newbury, I. Ishii, J. Stöhr, J.A. Horsley, R.D. Redwing, A.L. Johnson, F. Sette, J. Chem. Phys. 85 (1986) 4849.

[35] M.L. Gordon, D. Tulumello, G. Cooper, A.P. Hitchcock, P. Glatzel, O.C. Mullins, S.P. Cramer, U. Bergmann, J. Phys. Chem. A 107 (2003) 8512.

[36] W.H.E. Schwarz, T.C. Chang, U. Seeger, K.H. Hwang, Chem. Phys. 117 (1987) 73.

[37] S. Aminpirooz, L. Becker, B. Hillert, J. Haase, Surf. Sci. 244 (1991) 152.

[38] H. Schulz, Catal. Today 154 (2010) 183. 